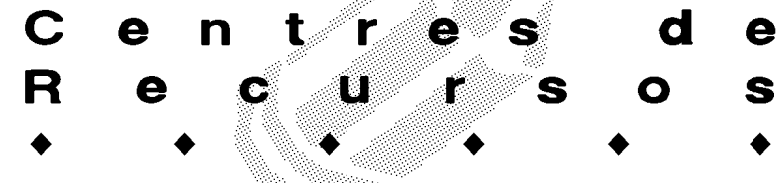

\title{
EL CENTRE DE RECURSOS PEDAGÒGICS DE LA TERRA ALTA
}

\author{
L'equip del CRP de la Terra Alta
}

\section{Presentació}

El Centre de Recursos Pedagògics de la Terra Alta és un servei educatiu del Departament d'Ensenyament, en funcionament des del curs 1988/89, atès per una plantilla de dues persones.

Els CRP són serveis educatius territorialitzats. És precisament aquesta característica pròpia del servei la que ens defineix millor. El context geogràfic és decisiu a l'hora de definir la tipologia d'un o diversos centres educatius i també ho és a l'hora de definir el CRP que els ofereix serveis.

Si la ruralitat és l'atribut més destacat de la Terra Alta, també ho és de les seues escoles i del seu CRP. Podem dir que el CRP de la Terra Alta atén les dotze escoles rurals de la comarca, així com l'IES Terra Alta de Gandesa, únic centre d'ensenyament secundari de la comarca, i l'Escola de Capacitació Agrària.

L'adequació entre el que ofereix el servei i el que ens demanen els centres i els seus docents és el que permet obtenir una millor eficàcia del servei del CRP, així com l'optimització dels recursos de què disposem. Aquesta adequació es concreta en el Pla de treball, de caràcter anual, i permet encabir actuacions diferents a un CRP de Tortosa, o de Tarragona, posem per cas, i on aspectes com el context geogràfic queden més palesos. A grans trets, podem dir que els dos grans blocs d'actuacions comunes a tots els CRP són els recursos educatius i les activitats de formació permanent del professorat.

\section{Recursos educatius}

Els recursos educatius són un suport imprescindible en la tasca docent del nostres centres. El CRP posa a l'abast de les escoles un seguit de llibres, dossiers, vídeos, diapositives, discs, cassettes, làmines, CD, software... pertanyents a la nostra Mediateca. El CRP disposa d'un servei de documentació que gestiona l'abundant informació existent. Això permet, per una banda, editar tot tipus de catàlegs perquè els docents coneguin aquest material i, per l'altra, oferir consultes $i$ assessoraments puntuals sobre recursos concrets. Totes dues actuacions estan encaminades a la consulta $i$ al préstec amb assessorament del material que es posa al servei dels centres educatius.

Les propostes editorials en el camp de l'estudi de l'entorn d'una comarca rural mostren clares deficiències. El CRP de la Terra Alta edita cada curs -amb els aparells de reprografia del servei- diversos quaderns d'estudi de cada poble, així com de la comarca, amb l'objectiu d'oferir recursos que pal-lïn part de les carències que esmentàvem anteriorment.

Un altre tipus de recurs que no es pot portar a l'aula en forma de llibre, vídeo o software, però d'unes grans possibilitats educatives, el conformen aquells museus,

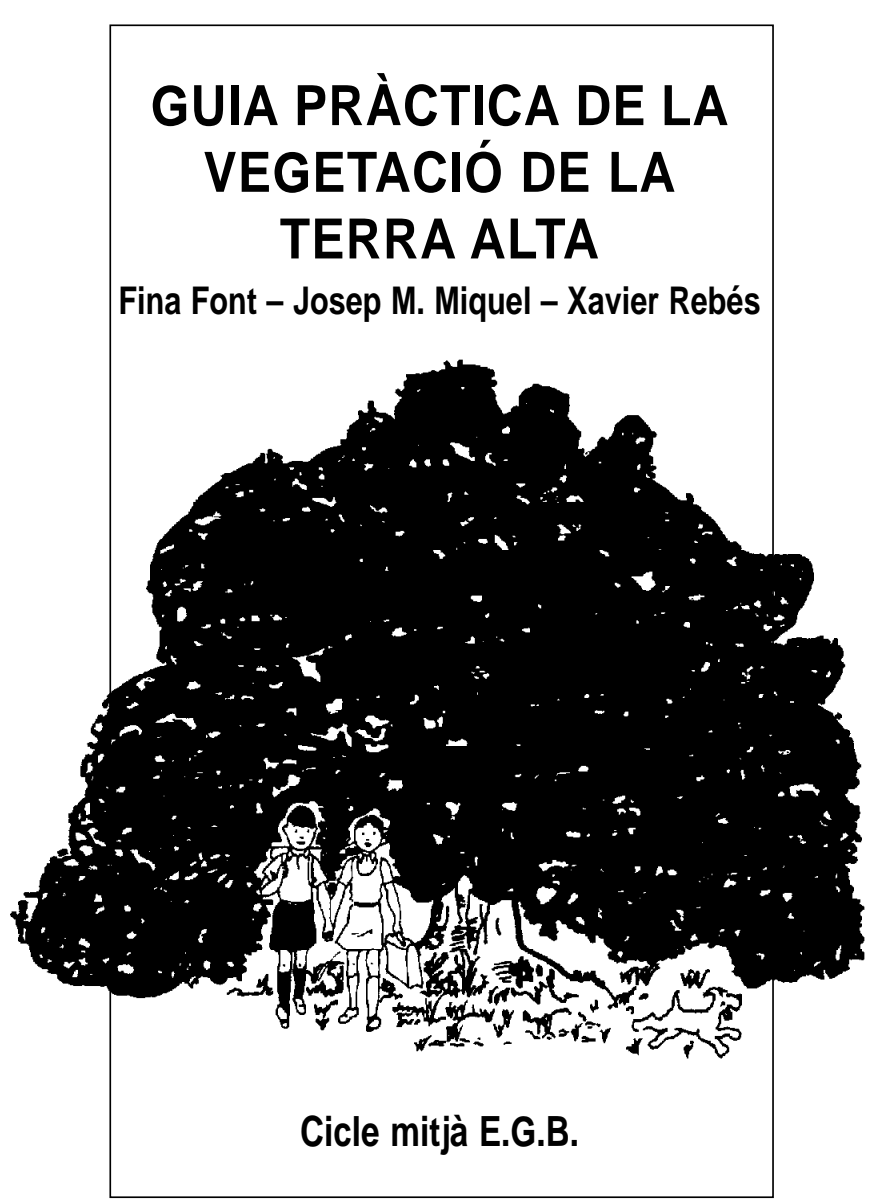




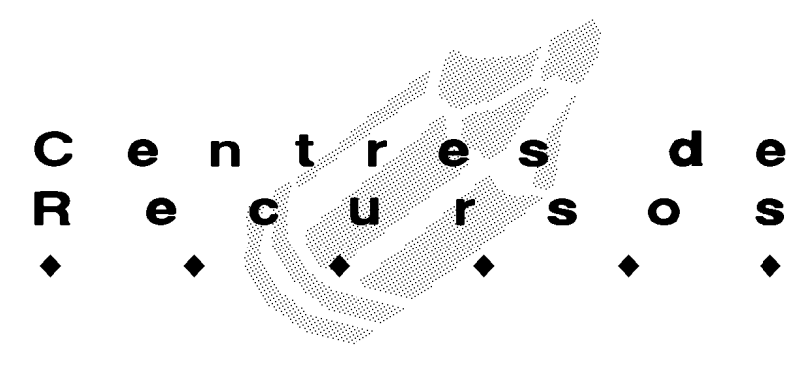

monuments, entitats, empreses, etc. del nostre entorn més proper. Les actuacions realitzades des del nostre CRP han estan la recollida i catalogació d'aquests recursos en una guia comarcal. En aquest moment es troba només pendent de la seua edició.

També voldríem ressaltar una altra tasca que en aquest moments només és un projecte, però d'un interès considerable: la confecció d'itineraris de visita dels diferents pobles de la comarca, amb els corresponents quaderns de treball per als alumnes. Aquest projecte permetrà un important suport pedagògic a les sortides escolars als pobles de la nostra comarca, ja sigui de centres del nostre àmbit d'influència o d'arreu del país.

\section{Formació permanent}

Des d'una comarca perifèrica i rural com la Terra Alta la participació del CRP en la gestió de les activitats

\section{ESTUDI DEL POBLE}

\section{ARNES}

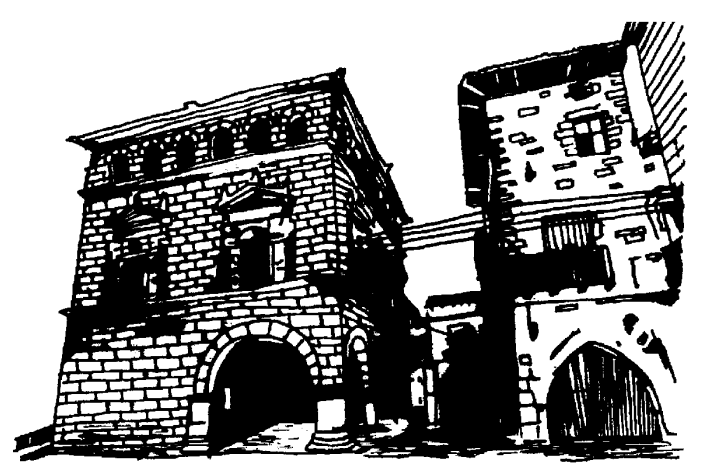

Investigador/a:

Escola: de formació permanent del professorat s'ha de considerar com un dels guanys rellevants de la territorialització del servei a la qual fèiem referència al començament de l'article. El fet de portar la formació permanent a la vora mateix del lloc de treball dels professionals de l'ensenyament ha multiplicat les possibilitats formatives dels nostres docents, sense necessitat de desplaçar-se molt lluny després de la seua jornada laboral. Les actuacions del CRP en aquest camp són les marcades per la normativa vigent, i destaca el seu paper en la detecció de necessitats de formació i en la part de gestió del procés que li correspon des de la difusió, a la inscripció i al suport a la infraestructura del tipus que sigui.

El PAFPZ (Pla d'Activitat de Formació Permanent de la Terra Alta) per al curs actual, el componen catorze activitats repartides en dos quadrimestres, de diverses modalitats i sorgides de les propostes del claustres. Segons les dades de matriculació del primer quadrimestre són quasi el 95\% dels docents de la comarca els que realitzen alguna activitat de formació permanent.

Si els dos blocs d'activitats esmentats fins ara són els més comuns a tots els CRP de la xarxa del Departament d'Ensenyament, en el nostre cas cal afegirhi un tercer bloc d'activitats d'un gran pes específic: les activitats pedagògiques i de suport als centres.

\section{Activitats pedagògiques i de suport als centres}

Mostra de Teatre Escolar de la Terra Alta.Enguany es celebra la desena edició, que està patrocinada per la Diputació de Tarragona i l'organitza una comissió formada per les escoles participants i el CRP. Es tracta d'una activitat interescolar molt consolidada a la comarca, amb participació de totes les escoles i de caràcter itinerant entre els diferents pobles de la comarca. L'activitat, a més dels aspectes pròpiament curriculars del joc dramàtic i l'expressió oral i corporal, té un component molt enriquidor de relació entre els alumnes dels diferents centres i de coneixença dels diferents pobles de la comarca.

Trobada interescolar de primavera. És una activitat amb participació de tots els alumnes d'ensenyament primari de la comarca. Té un caràcter eminentment cultural, relacional i festiu. A l'igual que la Mostra de Teatre, és de caire itinerant i al llarg de la jornada es duen a terme activitats com: cantada de cançons tradicionals, ballada de sardanes, projeccions de cinema o actuacions teatrals. S'organitza amb el finançament del Consell Comarcal i el suport del Departament de Cultura i l'Ajuntament del poble on tingui lloc la Trobada. 


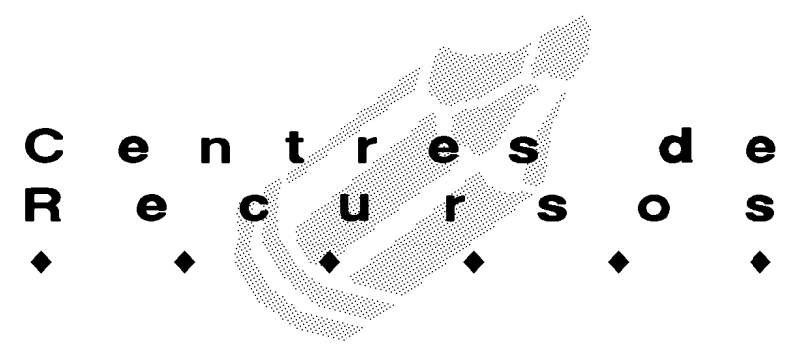

Recull de redaccions. S'organitza conjuntament amb el Consell Comarcal. El concurs serveix com a excusa perquè tots els escolars de la comarca escriguin al voltant d'un tema determinat -enguany, amb motiu de l'Any Europeu contra el racisme: "Tolerància i racisme"en un període de temps determinat. Amb la finalitat d'animar a la lectura i fomentar l'expressió escrita, totes les escoles reben lots de llibres i s'edita un recull dels treballs presentats.

Tallers educatius. Amb el suport pedagògic de la Cooperativa Abacus i el suport financer de la Federació de Cooperatives de Consumidors de Catalunya, el CRP organitza diferents tallers educatius referents a l'eix transversal de l'educació per al consum i de l'educació mediambiental. S'han realitzat tallers de piles usades, de reciclatge d'envasos o de compra de joguines.

100 llibres per a llegir! Des del curs 1995/96 el Centre de Recursos Pedagògics de la Terra Alta gestiona l'ús d'una minibiblioteca entre les escoles del seu àmbit d'influència. La minibiblioteca conté cent llibres cedits per ACALI per a cada curs escolar. A més de la maleta, els centres reben suggeriments d'activitats. L'ús d'aquest recurs, en servei de préstec per les diferents escoles de la comarca -amb la possibilitat de muntar diferents activitats com: racons de biblioteca, tallers de lectura, biblioteca de classe, etc.- suposa un suport rellevant a la motivació per a la lectura dels nostres alumnes.

Maletes pedagògiques i motxilles mediambientals. Eines per al foment de la creativitat i l'apropament de l'escola a l'entorn, respectivament, es tracta d'un seguit de recursos de caràcter innovador pertanyents als Programes Educatius de la Fundació "La Caixa" i que aquesta entitat cedeix als CRP perquè en gestionin el seu ús durant el curs escolar. Són recursos àgils $\mathrm{i}$ autònoms, fruit d'un procés de recerca experimental, que fan de pont entre l'entorn i el marc escolar. El CRP ofereix l'assessorament $i$ el suport necessari als centres per a el desenvolupament de les activitats proposades.

\section{Innovació educativa i intercanvi d'experiències}

EI CRP és l'element de continuïtat $i$ apropament entre el diferents programes educatius del Departament d'Ensenyament -programa d'Informàtica Educativa, de Mitjans Àudiovisuals, d'Educació per a la Salut a l'Escola...-i els centres docents.

Pel que fa a l'intercanvi d'experiències, durant el curs actual es concreta en un Pla de suport a les $Z E R$. Aquest curs 1997/98 s'ha posat en funcionament la primera $Z E R$ de la comarca. És previsible que això sigui el començament del procés de zonificació d'una comarca sobretot rural, com ja hem dit. L'intercanvi d'informacions, treballs, projectes... entre les escoles del nostre àmbit de treball $\mathrm{i}$ aquelles $Z E R$ en funcionament $\mathrm{i}$ ja consolidades entra dins de les actuacions previstes per a aquest curs.

Finalment, cal dir que aquest conjunt d'actuacions generades pel CRP o des de les mateixes escoles, així com un seguit d'informacions rellevants, han d'arribar

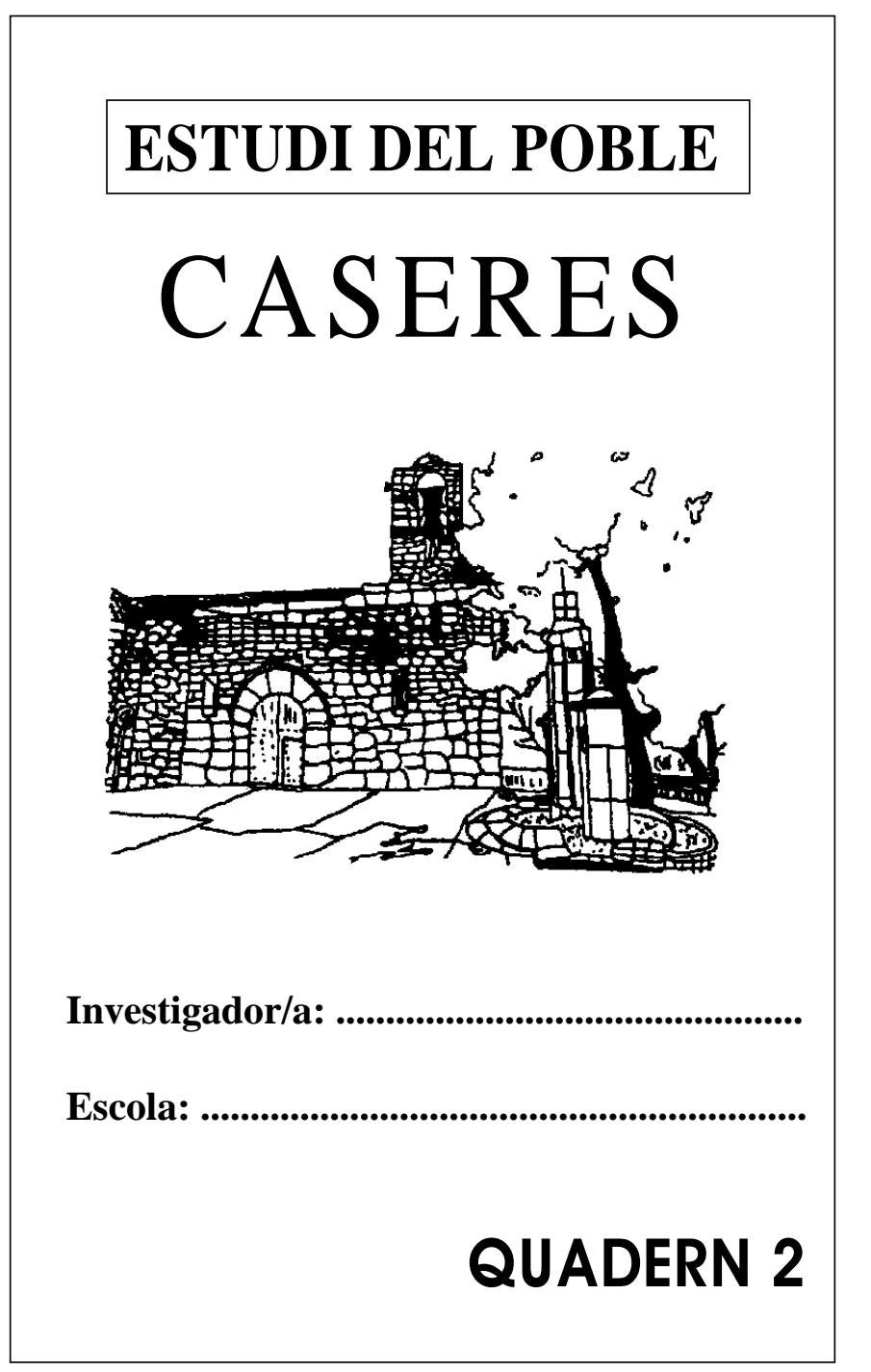

de forma regular i fluida a tots el docents de la comarca. Una part important del bon funcionament del CRP depèn de la bona comunicació amb les escoles i els docents que hi treballen. El Full informatiu que surt amb una periodicitat mensual és una de les eines. La creació d'una pàgina Web a Internet, un projecte. Aquest ens permetria arribar molt més lluny. 